\title{
Enhanced IoT-Based Climate Control for Oyster Mushroom Cultivation Using Fuzzy Logic Approach and NodeMCU Microcontroller
}

\author{
Muhammad Azizi Mohd Ariffin ${ }^{1 *}$, Muhammad Izzad Ramli ${ }^{1}$, Zarina Zainol ${ }^{1}$, \\ Mohd Nazrul Mohd Amin ${ }^{1}$, Marina Ismail ${ }^{1}$, Rosanita Adnan ${ }^{1}$, Nor Diana Ahmad ${ }^{1}$, \\ Norhasiah Husain ${ }^{2}$ and Nursuriati Jamil ${ }^{1}$ \\ ${ }^{1}$ National Autism Resource Centre, Faculty of Computer and Mathematical Sciences, UiTM, \\ Shah Alam, 40450, Malaysia \\ ${ }^{2}$ The National Autism Society of Malaysia, Pacific Place Commercial Centre, Unit B-2-3, B-3-3, Jalan PJU \\ 1A/4, Ara Damansara, 47301, Petaling Jaya, Selangor, Malaysia
}

\begin{abstract}
Urban farming has the potential to utilise unused space in the community to alleviate food shortages and increase the community's income through local food production. When Internet of Things (IoT) technology is integrated with urban farming, it can further improve its efficiencies and yield. The work in this paper improved our previous work of using an IoT-based climate control system to regulate the cultivation environment of oyster mushrooms automatically. Even though the climate control system could produce two batches of mushroom yields, there were several limitations, such as less efficient climate control due to threshold-based corrective action, water wastage, and system instability. This paper aims to address these stated limitations by implementing a fuzzy logic algorithm and redesigned the climate control

ARTICLE INFO

Article history:

Received: 16 April 2021

Accepted: 13 August 2021

Published: 22 October 2021

DOI: https://doi.org/10.47836/pjst.29.4.34

E-mail addresses:

mazizi@fskm.uitm.edu.my (Muhammad Azizi Mohd Ariffin) izzad@fskm.uitm.edu.my (Muhammad Izzad Ramli) zarina@fskm.uitm.edu.my (Zarina Zainol)

nazrul@fskm.uitm.edu.my (Mohd Nazrul Mohd Amin)

marina@fskm.uitm.edu.my (Marina Ismail)

rosanita@fskm.uitm.edu.my (Rosanita Adnan)

nordiana@fskm.uitm.edu.my (Nor Diana Ahmad)

norhasiah.husain@nasom.org.my (Norhasiah Husain)

lizajamil@computer.org (Nursuriati Jamil)

* Corresponding author

system. Two crisp input variables from DHT22 sensors representing temperature and humidity were fed into the Node MCU microcontroller's fuzzy logic coded in C language. The temperature and humidity conditions were divided into five fuzzy trapezoidal membership functions resulting in 25 fuzzy rules to control the duration of running the water pump and ventilation fan. An internal, lightweight web server were managed all HTTP client requests. The enhanced system also included a safety
\end{abstract}


measurement to avoid overheating the microcontroller and causing water wastage. Upon analysis of the data captured in two months, the result showed a decrease of $40 \%$ in water utilisation and an increase of mushrooms yield up to $226 \%$. The enhanced climate control system also facilitated maintaining and controlling the temperature and humidity conducive for optimal mushroom cultivation.

Keyword: Fuzzy logic, Internet of Things (IoT), node MCU microcontroller, oyster mushroom cultivation, urban farming

\section{INTRODUCTION}

Research of IoT utilisation in smart farming has increased tremendously, and this fact is reflected in the number of publications which has increased by $278 \%$ in 2017/2018 compared to 2016 (Navarro et al., 2020). In crop monitoring, big data analytics and machine learning techniques were largely used to predict environmental conditions (Adenugba et al., 2019), identify growth stages (Xia et al., 2018), and the health of plantations (Li et al., 2018). However, these technologies require massive resources and are more cost-benefitting for large plantations. In small-scale farming, particularly urban farming, IoTs are used mainly for crop monitoring and environment control. Urban farming can utilise unused space in the community to alleviate food shortages and increase the community's income through local food production (Poulsen et al., 2017). Oyster mushroom cultivation is among the top choice of crops for urban farming as it requires small space, has high nutritional and medicinal values and takes a shorter time to harvest (Nongthombam et al., 2021).

This paper presented an enhanced IoT-based climate control system for oyster mushroom cultivation, initially presented in the 10th Conference on System Engineering and Technology (ICSET) (Ariffin et al., 2020). In the previous IoT-based climate control system, fixed thresholds were used to automatically regulate the cultivation environment of oyster mushrooms in a mushroom house. Even though the IoT system alleviated the manual cultivation of oyster mushrooms at NASOM's (National Autism Society of Malaysia) Autism Care Centre in Bandar Puteri Klang, there were two limitations. The first limitation was the inability to regulate the mushroom house's environment to adapt to the weather changes during the wet and dry seasons. Malaysia experiences an equatorial climate with hot and humid weather for the whole year and two monsoon seasons from late May to September and October to March, respectively (Tang, 2019). The average temperature is $25.8^{\circ} \mathrm{C}$, with the highest at $30.3^{\circ} \mathrm{C}$ and the lowest at $21.9^{\circ} \mathrm{C}$ (Climate-Data.org., 2021). Malaysia also has a relatively high humidity with an average of $250 \mathrm{~cm}$ yearly rainfall (Saw, 2007). The rainy season occurs from November to January, while the drier season occurs from May to July (Wong et al., 2016). Ideally, the IoT system should perform a corrective action by turning on/off the ventilation fan and water pump on/off depending on the humidity and temperature changes due to the weather. Thus, the IoT system should 
automatically water the mushroom house during the dry season more frequently than the rainy season. However, since the control of the water pump and ventilation fan depended on pre-determined fixed thresholds, the same threshold values were used to control the climate of the mushroom house throughout the year. As a result, it has led to a less conducive environment for the cultivation of oyster mushrooms.

The second limitation is the wastage of water resources, again due to fixed thresholds and time intervals in controlling the water pump. For example, even though the relative humidity was high during the rainy season, the misting sprinkler was turned on according to the fixed intervals causing wastage of precious water resources. Therefore, it will contribute to the unsustainable use of water resources for agriculture (Al-Saidi \& Elagib, 2017). Moreover, the previous IoT system also frequently experienced system instability due to an unstable power source. The microcontroller and all the electronic components were placed together on a single breadboard (Figure 1).

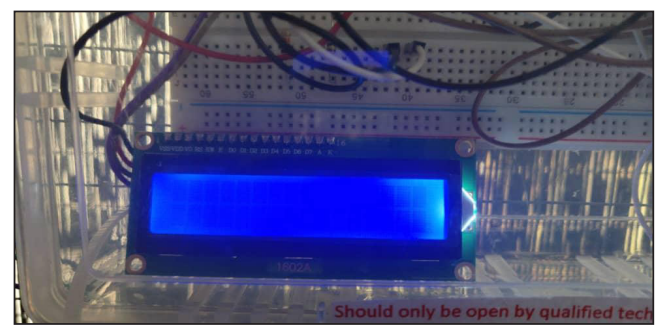

Figure 1. Blank LCD due to system error

Therefore, this paper proposed to overcome the limitation of using fixed thresholds to automatically control the climate of a mushroom house using a fuzzy logic approach and revised the system hardware specification to improve the system stability due to the power supply issues. The contribution of this paper is twofold: 1) This paper demonstrates the execution of an IoT climate control system in a mushroom house located in Bandar Puteri, Klang, Malaysia; and 2) This paper proved that the implementation of the fuzzy logic for IoT controller was able to provide better environmental management as required for mushroom cultivation and reduced the water usage resulted in a higher yield of harvested mushroom.

\section{RELATED WORK}

Machine learning and big data analytics were, and machine learning techniques were mainly used in large plantations for crop monitoring and by predicting the environmental conditions. Fuzzy logic is another option of crop monitoring and is commonly used to monitor multiple variables such as temperature and humidity in greenhouses and urban farming. Therefore, it is suitable for implementing a complex IoT system with multiple inputs and granular and dynamic action as an output (Krishnan et al., 2020). In Algarín et al. (2017) and Revathi and Sivakumaran (2016), a greenhouse's cooling and irrigation system was controlled using fuzzy logic. A heat loss gain method was used to compare the proposed system with the conventional manual method of controlling the light, temperature, humidity, and water supplied to the greenhouse. The results showed that the fuzzy logic control system needed approximately $25 \%$ less energy to heat the greenhouse. 
The authors further claimed that their proposed system contained more new technologies than previous similar work and allowed the crop to grow at the optimum level. However, the crop yields were not made available in the paper. Similarly, Alpay and Erdem (2018) used fuzzy logic to optimise the sensors' operations to monitor soil moisture, temperature, lighting, and relative humidity in a greenhouse. A greenhouse prototype using acrylic and aluminium was built for the sensors and fuzzy logic control system. When tested in realtime, the proposed fuzzy logic control system showed good stabilisation times (i.e., 4-10 mins) and average tolerances of 5\% for relative humidity, $2 \%$ for temperature, and $6 \%$ for soil moisture under different environmental conditions. However, the control system was tested in a controlled greenhouse prototype.

Implementation of IoT technology in mushroom cultivation was also commonly done, especially in Southeast ASEAN countries. Kassim et al. (2019) and Mat et al. (2019) developed a wireless sensor network system with a real-time embedded system to control temperature, humidity, and $\mathrm{CO}_{2}$ parameters to grow shiitake mushrooms in a controlled room of a building. Based on these parameters, the system provided feedback based on pre-defined thresholds to control the actuators attached to the exhaust fan, humidifier, circulation fan, and mist sprinkler. Even though the results showed 192.9\% of mushroom yields, the system was not implemented in a real environment. Ibrahim et al. (2018) monitored temperature, humidity, and $\mathrm{CO}_{2}$ in a smart mushroom house for three days and captured the sensor data in 3 minutes intervals. When the humidity in the mushroom house dropped below $75 \%$, a humidifier was activated until the humidity reached $85 \%$.

Meanwhile, the $\mathrm{CO}_{2}$ values were kept under 500ppm by turning on an exhaust fan whenever $\mathrm{CO}_{2}$ readings went over $600 \mathrm{ppm}$. The authors also showed that the average thickness per mushroom increased from $2.3 \mathrm{~cm}$ to $2.6 \mathrm{~cm}$, and its average weight attained $40 \mathrm{gm}$ compared to $35 \mathrm{gm}$ when using the conventional method. Najmurrokhman et al. (2020) implemented a similar IoT-based system using a closed box made of plastic to grow oyster mushrooms by monitoring the level of humidity and temperature. When the temperature and humidity reached above or under a set threshold, the lamp, fan, and mist sprinkler were turned on to reset the temperature and humidity to their respective fixed values. A further related literature search was done, and the summary is presented in Table 1. Based on Table 1, temperature and humidity are the two important parameters in mushroom cultivation. At the same time, $\mathrm{CO}_{2}$ is recommended for shitake mushrooms identified by Mat et al. (2019) and Ibrahim et al. (2018), especially in an enclosed room in a building where air circulation is stagnant (Mat et al., 2019; Shakir et al., 2019). In their control setup, Shakir et al. (2019) also added a light intensity parameter to light up the enclosed room after $6.00 \mathrm{pm}$. They observed the increase of $\mathrm{CO}_{2}$ level in the presence of artificial light, indicating the mushrooms produced more $\mathrm{CO} 2$ when the light was turned on. Therefore, our study omitted $\mathrm{CO} 2$ as the observed parameter as the focus is oyster mushroom cultivation, and the mushroom house has good air circulation. 
Table 1 also showed that while the use of fuzzy logic control systems was beginning to be implemented in recent years, most mushroom cultivations still relied on utilising fixed thresholds to monitor temperature and humidity. Even though Chieochan et al. (2017) and Boonchieng et al. (2018) reported a ten times reduction in labour costs of mushroom cultivation when they implemented an IoT-based monitoring system using fixed thresholds in a mushroom hut, they did not report on the mushroom yields. Cruz-Del Amen and Villaverde (2019) and Hendrawan et al. (2019) used fuzzy logic to control temperature and humidity in their oyster mushroom cultivations. While Cruz-Del Amen and Villaverde (2019) conducted their experiments in a controlled enclosed space, the latter implemented the testing using a plastic container box.

Table 1

Summary of selected IoT-based mushroom cultivations work

\begin{tabular}{|c|c|c|c|c|c|}
\hline \multirow{2}{*}{ Authors } & \multicolumn{3}{|c|}{ Controlled parameters } & \multirow{2}{*}{ Cultivation setup } & \multirow{2}{*}{$\begin{array}{l}\text { Monitoring } \\
\text { technique }\end{array}$} \\
\hline & Temperature & Humidity & $\mathrm{CO}_{2}$ & & \\
\hline Ibrahim et al. (2018) & $\sqrt{ }$ & $\sqrt{ }$ & $\sqrt{ }$ & Mushroom house & Fixed threshold \\
\hline $\begin{array}{l}\text { Kassim et al. (2019) } \\
\text { Mat et al. (2019) }\end{array}$ & $\sqrt{ }$ & $\sqrt{ }$ & $\sqrt{ }$ & Building room & Fixed threshold \\
\hline Najmurrokhman et al. (2020) & $\sqrt{ }$ & $\sqrt{ }$ & & Mocked prototype & Fixed threshold \\
\hline $\begin{array}{l}\text { Chieochan et al. (2017) } \\
\text { Boonchieng et al. (2018) }\end{array}$ & $\sqrt{ }$ & $\sqrt{ }$ & & Mushroom hut & Fixed threshold \\
\hline Shakir et al. (2019) & $\sqrt{ }$ & $\sqrt{ }$ & $\sqrt{ }$ & Building room & Fixed threshold \\
\hline $\begin{array}{l}\text { Cruz-Del Amen and } \\
\text { Villaverde (2019) }\end{array}$ & $\sqrt{ }$ & $\sqrt{ }$ & & $\begin{array}{l}\text { Controlled enclosed } \\
\text { space }\end{array}$ & Fuzzy logic \\
\hline Hendrawan et al. (2019) & $\sqrt{ }$ & $\sqrt{ }$ & & $\begin{array}{l}\text { Plastic container } \\
\text { box }\end{array}$ & Fuzzy logic \\
\hline
\end{tabular}

This paper differs from work in the literature where the mushroom cultivation was done in a real mushroom house exposed to pest threats, unpredictable weather, and noisy environments from car traffic. This paper reports on the experiences, challenges, and limitations of implementing a fuzzy control climate system for cultivating oyster mushrooms within two months.

\section{METHODOLOGY}

The IoT-Based climate control system was implemented in a mushroom house at NASOM's Autism Care Centre in Bandar Puteri Klang, Malaysia. First, the primary data from the sensors were captured. The captured data were average temperature, humidity, mushroom yield, and water usage. The data analysis was then conducted and compared with our first IoT-based system that used fixed thresholds. 


\section{System Design}

The improved IoT-based climate control design was divided into three sections: Oyster Mushroom Cultivation Environment, IoT-Based Climate Control System, Fuzzy Logic Algorithm, and Web Interface.

\section{Oyster Mushroom Cultivation Environment}

Oyster mushroom has a specific growing environment to ensure healthy and productive yield. It needs to grow in a temperature range of $22-28^{\circ} \mathrm{C}$ and humidity range of $60-80 \%$ (Adhitya et al., 2017). Thus, a farmer would manually spray water to the floor to control the temperature and humidity level in the conventional cultivation method. However, the mushrooms cannot contact directly with the water as a wet growing medium will damage the mushroom with bacterial or fungal infection (Hamidizade et al., 2020). Moreover, the mushroom also needs to be protected from insects, pests, or bad odour to ensure quality yield. Therefore, to grow and cultivate oyster mushrooms in a controlled environment, farmers grow oyster mushrooms inside a mushroom house. However, maintaining a conventional mushroom house is tedious as a farmer needs to control the climate inside the mushroom house manually. Thus, this paper proposed a smart mushroom powered by an enhanced IoT-based climate control using the fuzzy logic system. Figure 2 shows the physical arrangement of the smart mushroom house.

The size of the smart mushroom house is $547 \times 347 \mathrm{~cm}$, and it consists of several components such as the IoT Control Box, Access Point, Water Pump, Exhaust Fan, Sensors, and Rack. The mushroom house can fit ten racks for holding up to 2,000 blocks of oyster

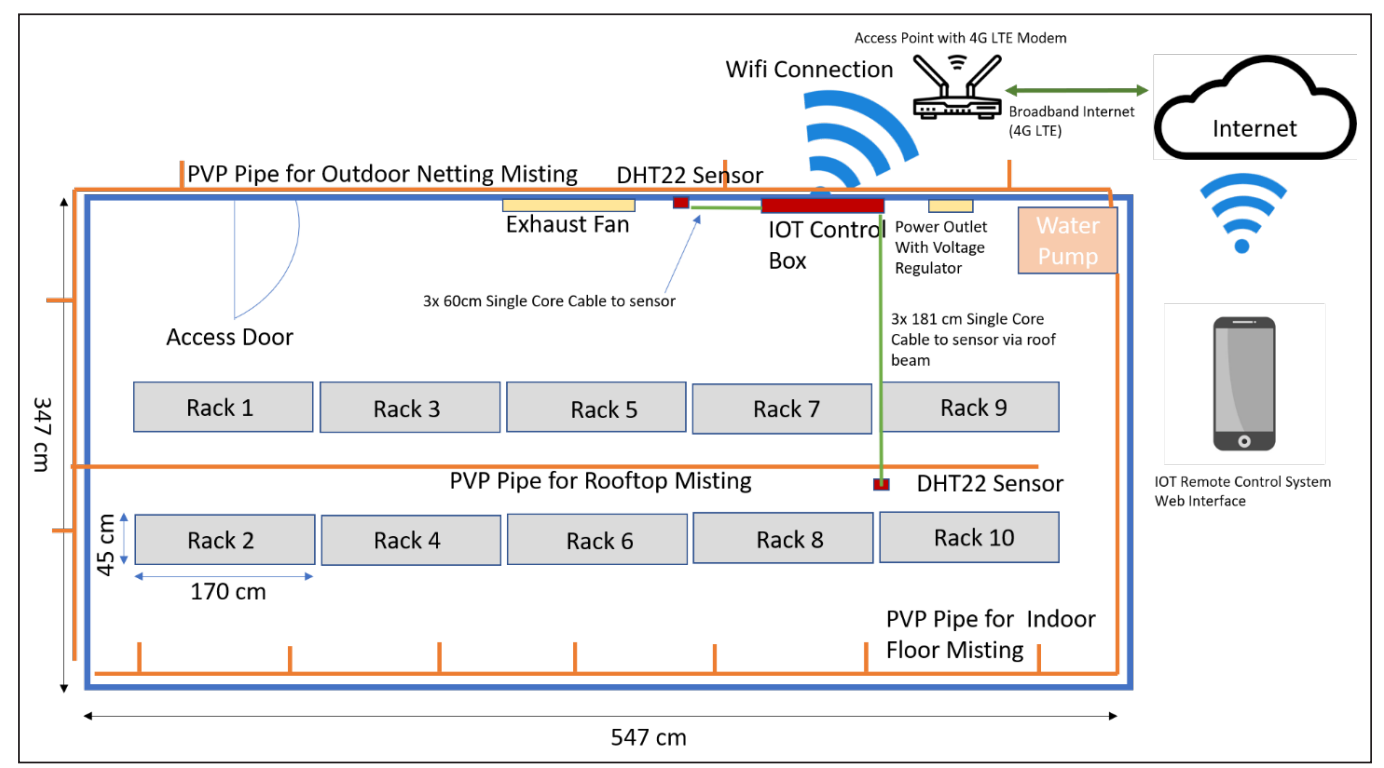

Figure 2. Mushroom house with IoT-based climate control physical arrangement 
mushroom growing medium. The racks holding the growing medium were rearranged to improve the air circulation. Based on our earlier experiences, the vertical arrangement of the racks did not allow optimal airflow, and the mushroom blocks got easily wet during heavy rains. Therefore, the racks were subsequently horizontally rearranged, as shown in Figure 2, to ensure optimal air circulation and easy access to the growing medium. The IoT control box hosted the Node MCU Microcontroller, which contained the fuzzy logic to control the ventilation fan and water pump automatically. Two DHT22 sensors were placed at the ceiling and connected to the Node MCU for capturing temperature and humidity inside the mushroom house. The connection between the microcontroller and the sensor was via three single-core wires of size $0.5 \times 0.25 \mathrm{~mm}$. The length of the connection wire to the first sensor was $60 \mathrm{~cm}$, while the second sensor was located $180 \mathrm{~cm}$ from the IoT box, and the wire was placed along the roof beam. The power for the IoT control box was supplied by a power outlet equipped with a voltage regulator to ensure a stable supply of 5V 2A DC electricity. The mushroom house was also equipped with an access point with a built-in 4G LTE Modem to connect the IoT control box. Internet connectivity was used to display the climate data to the end-user via a web interface and enabled the end-user to control the IoT system remotely.

The purpose of the ventilation fan was to pump out hot air from inside the mushroom house and ensure optimal air circulation, which was vital for oyster mushroom cultivation (Wahab et al., 2019). On the other hand, the water pump was connected to the PVC pipes to supply water to the misting head to spray the floor and the roof to regulate the temperature inside the mushroom house. Unfortunately, the climate control system was not equipped with a nozzle head to spray the roof in our initial work. Thus, the enhanced climate control system added water nozzles on top of the roof to further improve temperature regulation in the mushroom house. Furthermore, since the mushroom house is located on a busy road in an urban area, the heat from the traffic contributed to the high-temperature occurrence. Lastly, the bottom half of the mushroom house wall was built using bricks. At the same time, the upper part was installed with steel netting and agriculture grade black netting to protect the mushroom house from pest invasions and ensure proper air circulation.

\section{IoT-Based Climate Control System}

The system's intelligence to control climate and regulate the environment was in the fuzzy logic algorithm running in the Node MCU microcontroller. Figure 3 shows the logical diagram of the IoT-based climate control system. First, the temperature and humidity crisps value inputs to the system. The crisps values were converted to a fuzzy value using a trapezoidal fuzzifier function. At the same time, the crisps values were also sent to a light web server so that they can be displayed to LCD via GPIO and web interface via network communication. After the crisp values were converted, they were fed to the fuzzy logic function for further processing. 
Muhammad Azizi Mohd Ariffin, Muhammad Izzad Ramli, Zarina Zainol, Mohd Nazrul Mohd Amin, Marina Ismail, Rosanita Adnan, Nor Diana Ahmad, Norhasiah Husain and Nursuriati Jamil

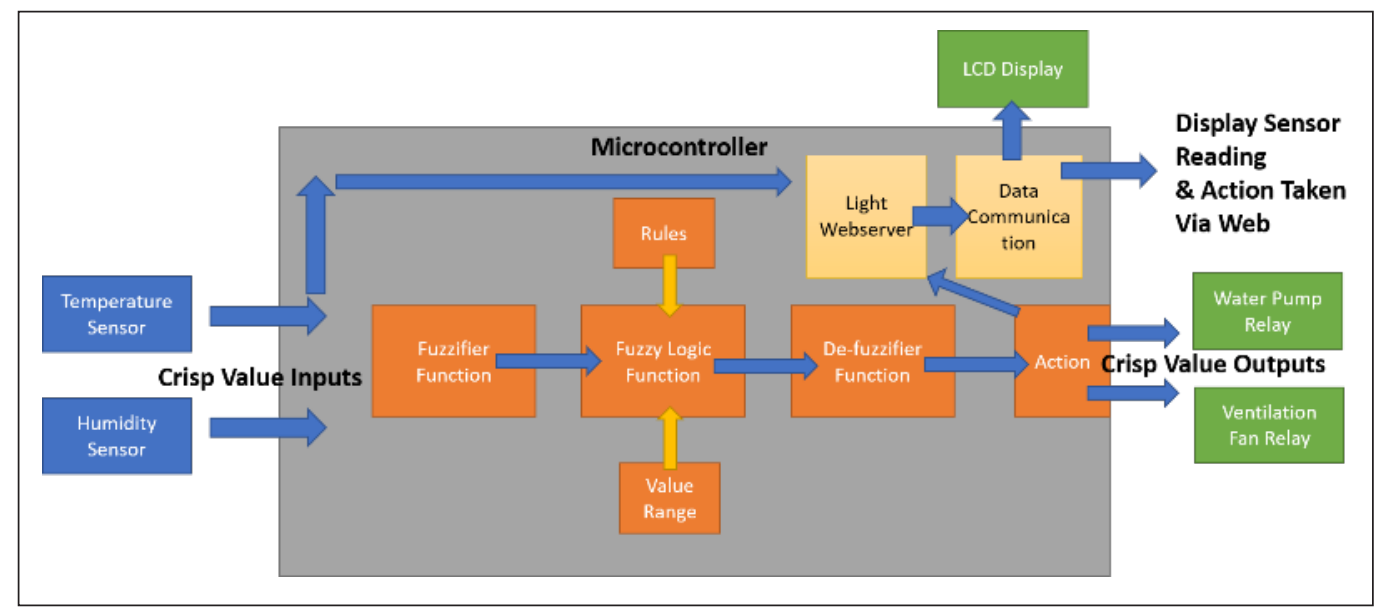

Figure 3. System logical diagram

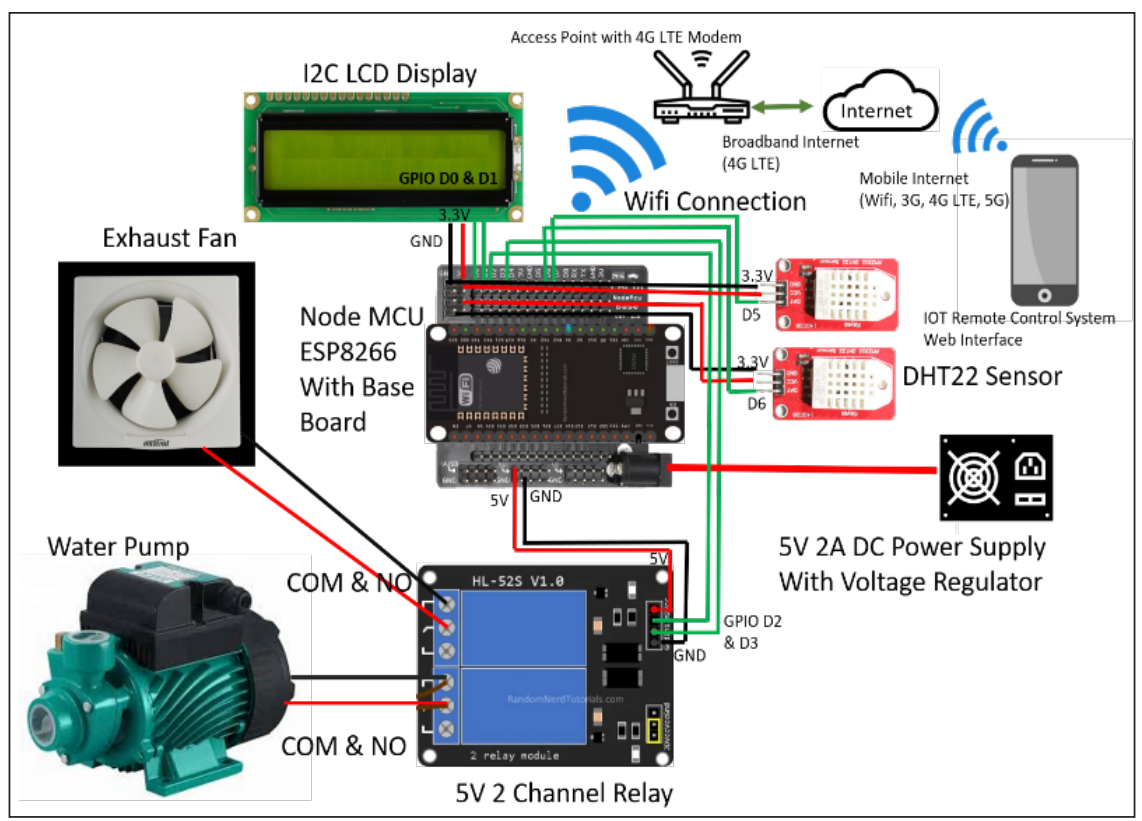

Figure 4. IoT based climate control hardware schematic.

The fuzzy logic algorithm checked the fuzzy rules and depending on the fuzzy input. Then, the algorithm inferred a suitable value range for the fuzzy output. After that, the fuzzy output was sent to the defuzzifier function to be converted back to the crisp value. The crisp value determined the action taken by the system to regulate the mushroom house. An example of such action was turning on the water pump for 30 seconds and the ventilation fan for 40 seconds due to Hot Temperature. The hardware schematic for implementing the enhanced IoT system is shown in Figure 4. 
The system used Node MCU Microcontroller equipped with an ESP8266 chip Base Board to run the fuzzy logic and connect with the sensors and relays. Node MCU was used extensively by various IoT and Wireless sensor network projects due to its capability to connect to the Internet via Wi-Fi using very low power and miniature configuration (Kashyap et al., 2018). The width of the Node MCU board is only $30 \mathrm{~mm}$ and equipped with integrated GPIO, PWM, IIC, 1-Wire, and ADC all in one board. The Node MCU board provided an easy connection with the sensors, relay, and I2C LCD. Furthermore, it also ensured stable power input with an onboard $5 \mathrm{~V}$ voltage regulator capable of the maximum voltage output of $1 \mathrm{~A}$. In our initial climate control system, the microcontroller was only connected to the breadboard without any baseboard. It has caused instability to the system due to a lack of voltage regulators and proper pin connection. The DHT22 sensor module measured temperature in $-40^{\circ} \mathrm{C}$ to $80^{\circ} \mathrm{C}$ and humidity range of 0 to $100 \%$. It has $+-2 \%$ RH accuracy, +-0.5 degrees ${ }^{\circ} \mathrm{C}$ accuracy, and the ability to read data every 2 seconds (CircuitSchools Staff, 2020). The ventilation fan and the 240V AC water pump were controlled by the control climate system using 5V 2 Channel relay. Meanwhile, the I2C LCD displayed current sensor reading, action, and any error logs. A stable power supply was ensured by a power outlet equipped with a voltage regulator to ensure a stable supply of 5V 2A DC electricity.

\section{Fuzzy Logic Algorithm}

The first stage in constructing the fuzzy logic algorithm involved defining the linguistic variables and terms for the input and output; constructing the fuzzy logic membership functions and the rule base. The input variables were temperature and humidity; the linguistic terms for temperature were \{Too cold, Cold, Normal, Hot, Too hot\} and the trapezoidal membership function simulated in MATLAB was constructed as shown in Figure 5. The 'Normal' temperature ranges from 22 to $29^{\circ} \mathrm{C}$, which is the desirable state of temperature for the best yield of the mushrooms.

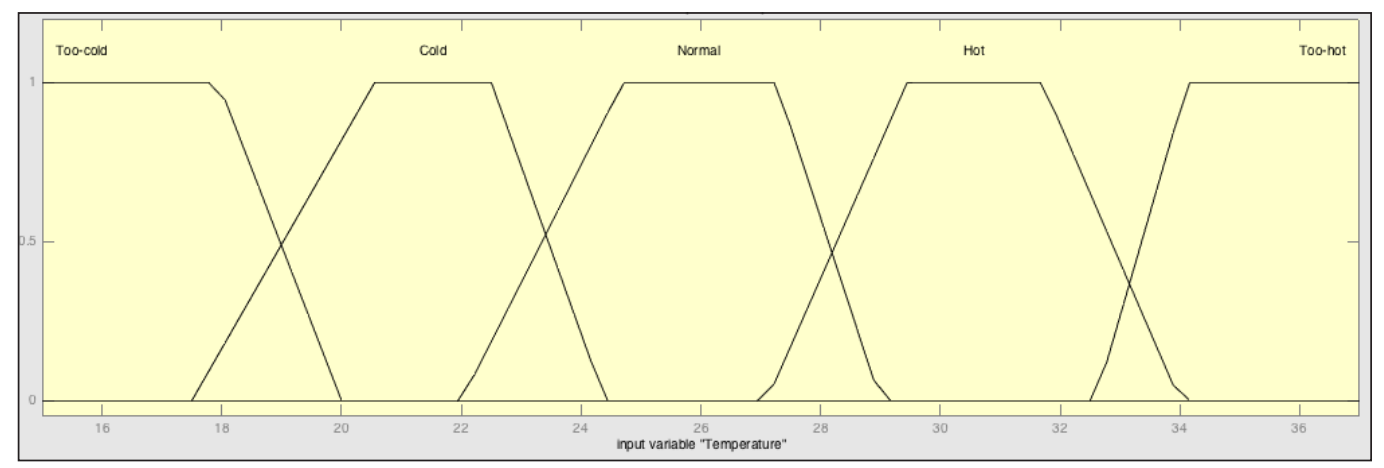

Figure 5. Trapezoidal membership function with fuzzy sets for temperature 
Humidity was defined as \{Too humid, Humid, Normal, Dry, Too Dry\}, and its trapezoidal membership function can be seen in Figure 6. The fuzzy set for ideal humidity of the mushrooms ranges from 71 to $84 \%$, and the climate control system commanded the ventilation fan and water pump accordingly to maintain the humidity.

Duration of the ventilation fan and water pump were the output variables, and the linguistic terms for the duration were \{Slow, Medium, Long\}. The trapezoidal membership functions for the ventilation fan and water pump duration are shown in Figures 7 and 8, respectively. The fuzzy data

Table 2

Membership functions with fuzzy sets for the duration of ventilation fan and water pump

\begin{tabular}{lcc}
\hline Output & $\begin{array}{c}\text { Ventilation fan } \\
(\mathrm{sec})\end{array}$ & $\begin{array}{c}\text { Water pump } \\
(\mathrm{sec})\end{array}$ \\
\hline Short & $0-93$ & $0-93$ \\
Medium & $80-173$ & $66-173$ \\
Long & $165-250$ & $146-250$ \\
\hline
\end{tabular}
sets for the ventilation fan and water pump are shown in Table 2.

The knowledge base rules are shown as a matrix in Table 3 containing 25 rules according to the Mamdani fuzzy inference system. The rules were used to decide the duration of the ventilation fan and water pump in 3 membership degrees of Short, Medium, and Long. Three examples of the rules in the knowledge base were:

Rule 1: IF Temperature is (Too Cold OR Cold) AND Humidity is Too Humid THEN Action is Long Duration (Fan)

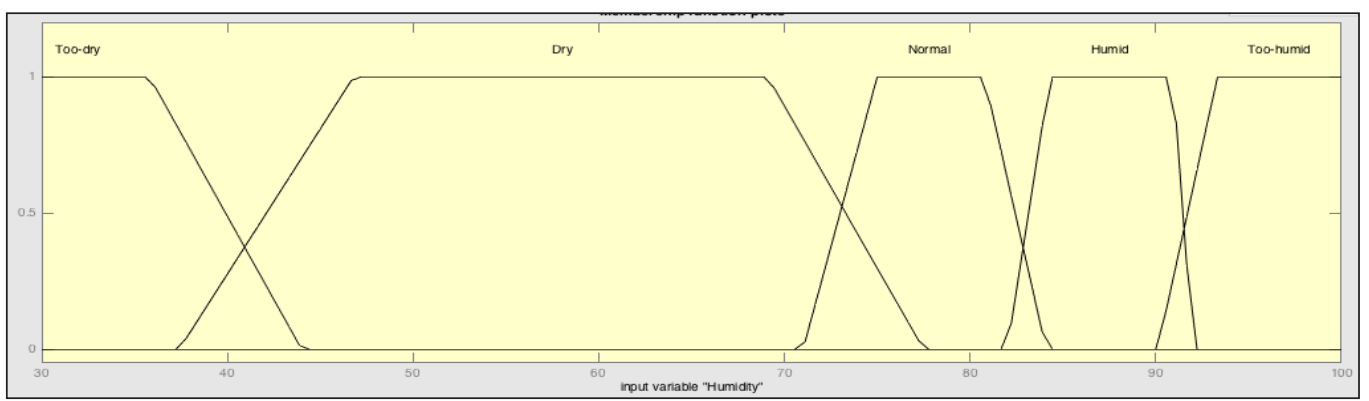

Figure 6. Trapezoidal membership function with fuzzy sets for humidity

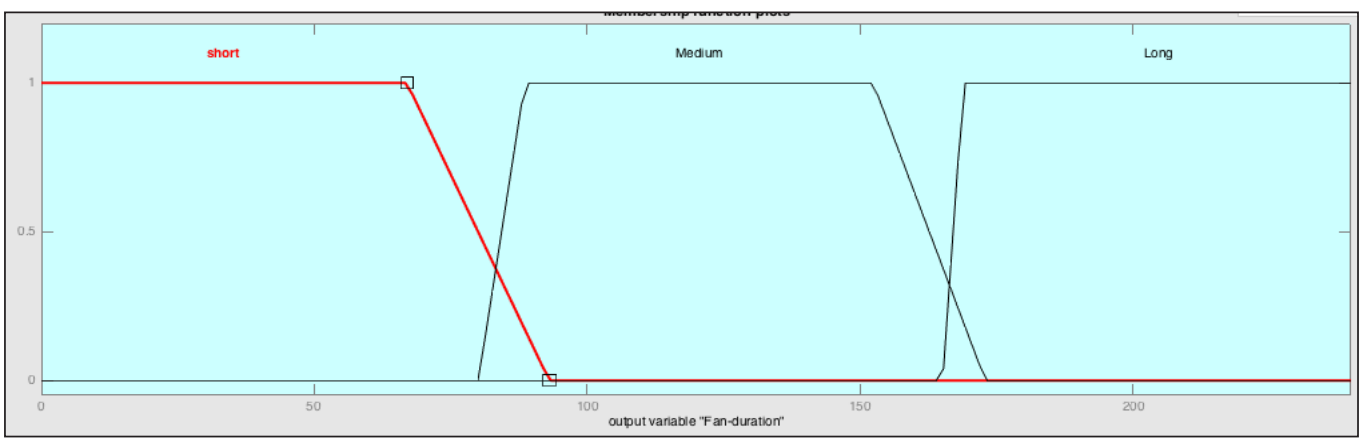

Figure 7. Trapezoidal membership function with fuzzy sets of the duration for ventilation fan 


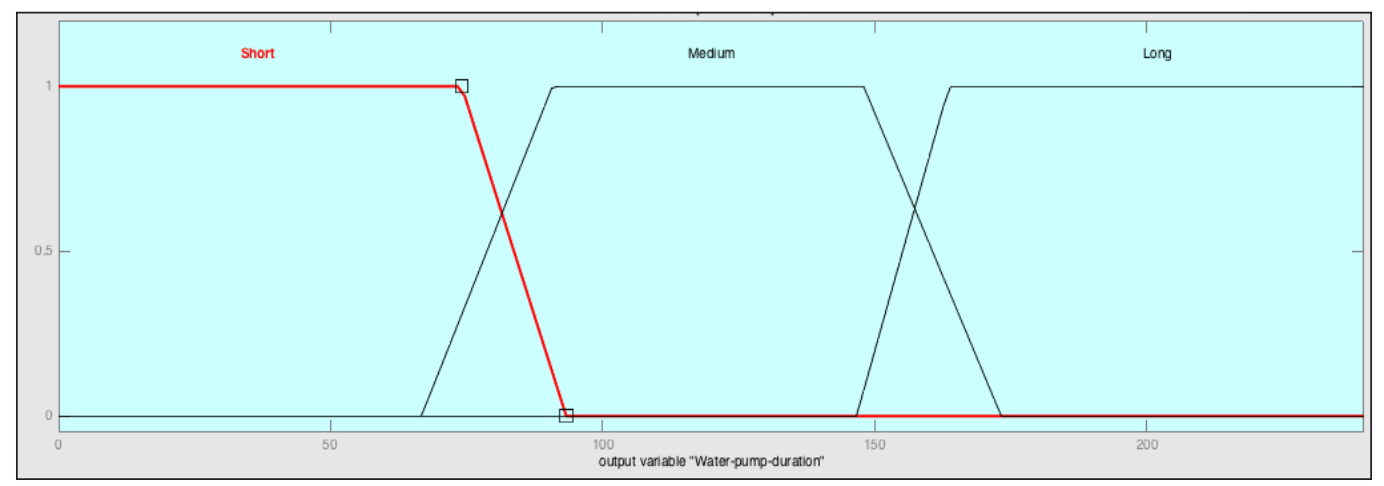

Figure 8. Trapezoidal membership function with fuzzy sets of the duration for water pump

Table 3

Fuzzy rules and action taken using rules based on Mamdani fuzzy inference system

\begin{tabular}{|c|c|c|c|c|c|}
\hline $\begin{array}{l}\text { Temperature / } \\
\text { Humidity }\end{array}$ & Too Humid & Humid & Normal & Dry & Too Dry \\
\hline Too Cold & $\begin{array}{l}\text { Long duration } \\
\text { (fan) }\end{array}$ & $\begin{array}{l}\text { Long duration } \\
\text { (fan) }\end{array}$ & $\begin{array}{l}\text { Medium } \\
\text { duration (fan) } \\
\text { and short } \\
\text { duration (water } \\
\text { pump) }\end{array}$ & $\begin{array}{l}\text { Short duration } \\
\text { (fan) and } \\
\text { medium } \\
\text { duration (water } \\
\text { pump) }\end{array}$ & $\begin{array}{l}\text { Short duration } \\
\text { (fan) and long } \\
\text { duration (water } \\
\text { pump) }\end{array}$ \\
\hline Cold & $\begin{array}{l}\text { Long duration } \\
\text { (fan) }\end{array}$ & $\begin{array}{l}\text { Medium } \\
\text { duration (fan) }\end{array}$ & $\begin{array}{l}\text { Short duration } \\
\text { (fan) and (water } \\
\text { pump) }\end{array}$ & $\begin{array}{l}\text { Short duration } \\
\text { (fan) and } \\
\text { medium } \\
\text { duration (water } \\
\text { pump) }\end{array}$ & $\begin{array}{l}\text { Short duration } \\
\text { (fan) and long } \\
\text { duration (water } \\
\text { pump) }\end{array}$ \\
\hline Normal & $\begin{array}{l}\text { Short duration } \\
\text { (fan) }\end{array}$ & $\begin{array}{l}\text { Short duration } \\
\text { (fan) }\end{array}$ & $\begin{array}{l}\text { Short duration } \\
\text { (fan) and (water } \\
\text { pump) }\end{array}$ & $\begin{array}{l}\text { Short duration } \\
\text { (fan) and } \\
\text { medium } \\
\text { duration (water } \\
\text { pump) }\end{array}$ & $\begin{array}{l}\text { Short duration } \\
\text { (fan) and long } \\
\text { duration (water } \\
\text { pump) }\end{array}$ \\
\hline Hot & $\begin{array}{l}\text { Medium duration } \\
\text { (fan) and (water } \\
\text { pump) }\end{array}$ & $\begin{array}{l}\text { Medium } \\
\text { duration (fan) } \\
\text { and (water } \\
\text { pump) }\end{array}$ & $\begin{array}{l}\text { Long duration } \\
\text { (fan) and (water } \\
\text { pump) }\end{array}$ & $\begin{array}{l}\text { Long duration } \\
\text { (fan) and (water } \\
\text { pump) }\end{array}$ & $\begin{array}{l}\text { Long duration } \\
\text { (fan) and (water } \\
\text { pump) }\end{array}$ \\
\hline Too Hot & $\begin{array}{l}\text { Long duration } \\
\text { (fan) and (water } \\
\text { pump) }\end{array}$ & $\begin{array}{l}\text { Long duration } \\
\text { (fan) and } \\
\text { (water pump) }\end{array}$ & $\begin{array}{l}\text { Long duration } \\
\text { (fan) and (water } \\
\text { pump) }\end{array}$ & $\begin{array}{l}\text { Long duration } \\
\text { (fan) and (water } \\
\text { pump) }\end{array}$ & $\begin{array}{l}\text { Long duration } \\
\text { (fan) and (water } \\
\text { pump) }\end{array}$ \\
\hline
\end{tabular}

Rule 2: IF Temperature is (Hot OR Too Hot) AND Humidity is Too Dry THEN (Action is Long Duration (Fan) AND Long Duration (Water Pump))

Rule 3: IF Temperature is Too Cold AND Humidity is Normal THEN (Action is Medium Duration (Fan) AND Short Duration (Water Pump))

In the fuzzification stage, the crisp input values of humidity and temperature were converted to fuzzy values using the constructed trapezoidal membership functions. 
The graphical user interface to design the fuzzy logic is shown in Figure 9, while the defuzzification is described in Figures 10 and 11, respectively. The fuzzification used Max and Min for Boolean operations OR and AND, respectively. The results were fuzzy values for the duration of the ventilation fan and water pump. The defuzzification stage was then performed according to the respective membership functions using the centre of gravity ('centroid') algorithm to obtain the crisp output value for durations.

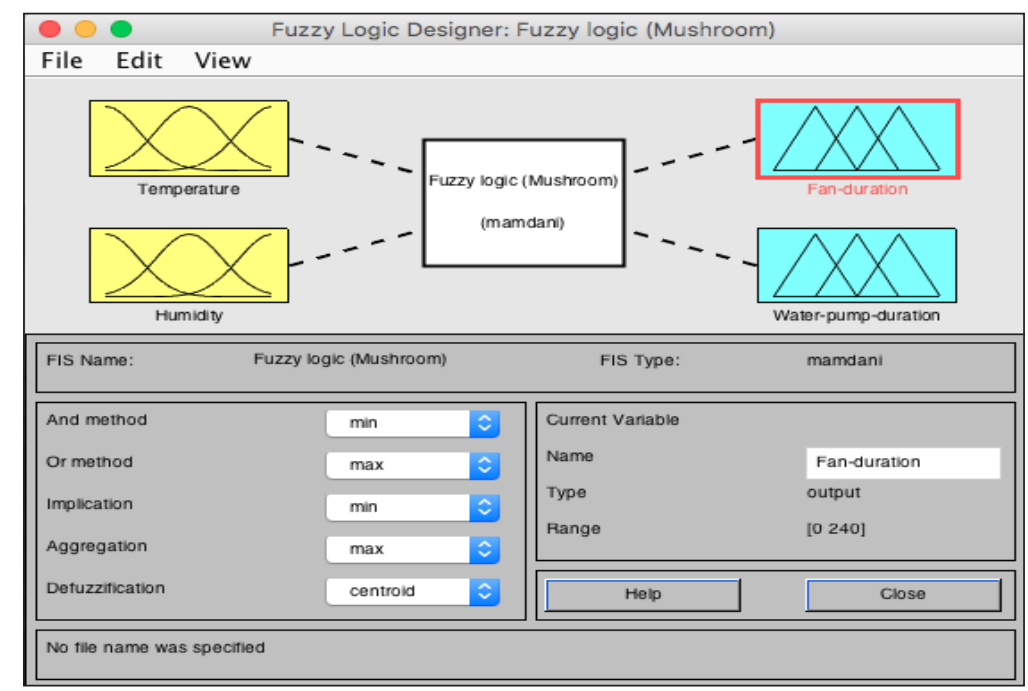

Figure 9. The graphical user interface of the enhanced fuzzy logic-based system by using the Mamdani fuzzy inference system

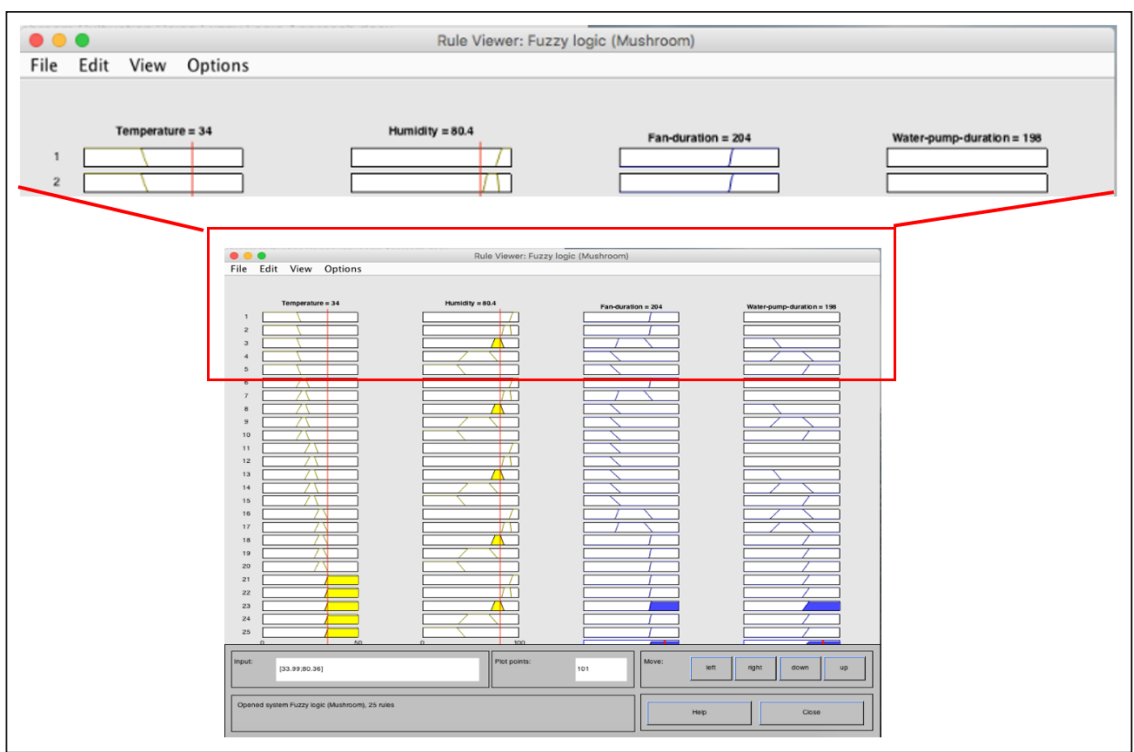

Figure 10. Simulation result for input variables with the temperature value equals to $34^{\circ} \mathrm{C}$ and the humidity value is equal to $80.4 \%$ 
In Figure 10, the crisp input values for temperature and humidity were $34^{\circ} \mathrm{C}$ and 80.4 $\%$, respectively. The fuzzy logic then executed the rule "IF Temperature is (Hot OR Too Hot) AND Humidity is Normal THEN (Action is Long Duration (Fan) AND Long Duration (Water Pump)" and resulted in turning on the ventilation fan for 204 seconds and the water pump running for 198 seconds.

Figure 11 demonstrates another example of the fuzzy logic system with an input temperature of $16.4^{\circ} \mathrm{C}$ and a humidity value of $38.9 \%$. The fuzzy rule "IF Temperature is (Too Cold OR Cold) AND Humidity is Too Dry THEN (Action is Short Duration (Fan) AND Long Duration (Water Pump) was initiated, and the output resulted in turning on the ventilation fan for 42 seconds and the duration of the water pump for 180 seconds.

The simulated fuzzy logic algorithm was tested based on actual data collected from the sensors, and the actions taken were validated based on the input variables. Finally, the fuzzy logic algorithm was coded in C language and implemented in the NodeMCU controller for the proposed enhanced IoT-based climate control system.

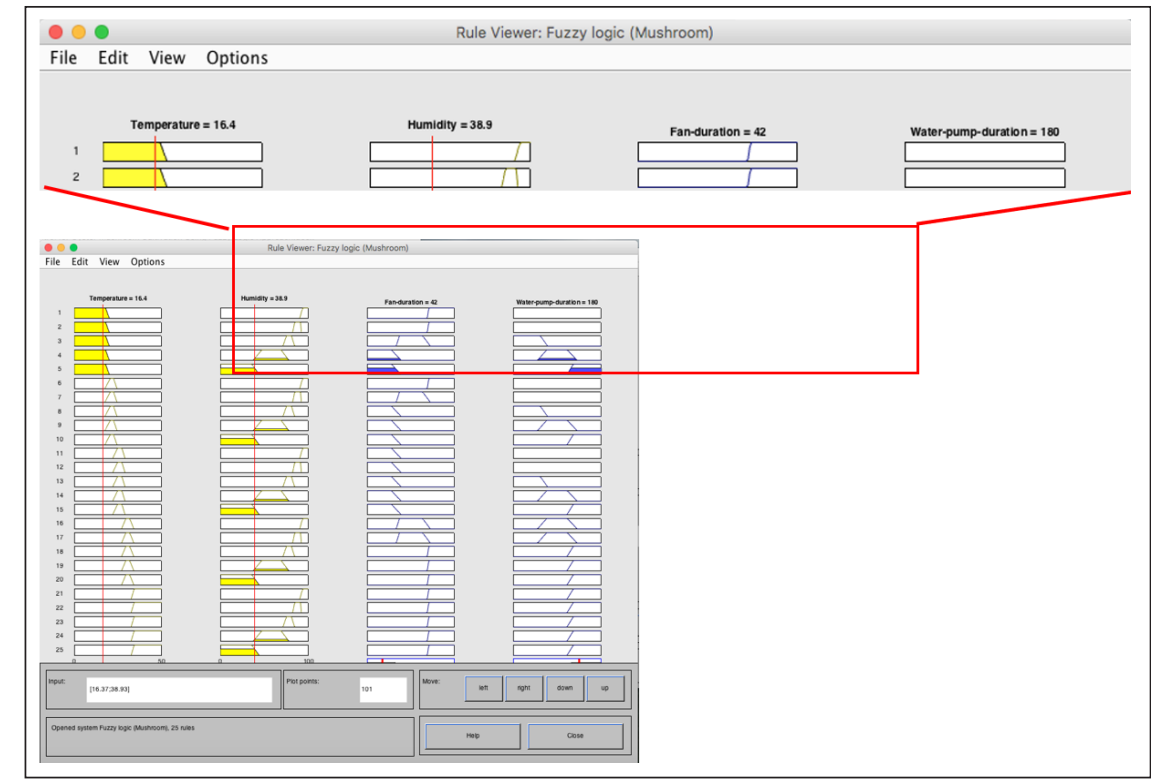

Figure 11. Simulation result for input variables with the temperature value equals $16.4^{\circ} \mathrm{C}$ and the humidity value is equal to $38.9 \%$

\section{Web Interface}

The IoT system has a web interface that displays the end-users sensor reading, action is taken, and system uptime. It was connected to the Internet, which enabled the end-users to access the web interface remotely via a web browser with Internet access availability. The NodeMCU microcontroller has adequate processing power to run a lightweight web server inside its system. The web server was implemented using built-in Arduino's ESP8266 
Web server function to listen to HTTP client requests. Simple HTML code was written to display the sensor reading. This project retained the same web interface layout as our previous work, as illustrated in Figure 12.

\section{Summary of System Design}

As this paper improves the IoT-based climate control system proposed in Ariffin et al. (2020), comparisons of features and specifications are presented in Table 4.

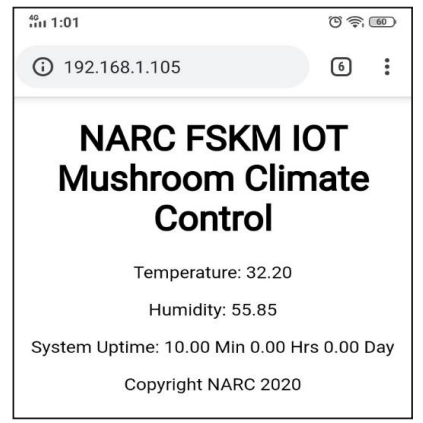

Figure 12. System web interface

Table 4

Summary of improved features and specifications compared to Ariffin et al. (2020)

\begin{tabular}{|c|c|c|c|}
\hline No & Features / Specification & Ariffin et al. (2020) & Enhanced System Design \\
\hline 1. & Microcontroller Logic & Threshold-based Logic & Fuzzy Logic \\
\hline 2. & Power \& Connection & $\begin{array}{l}\text { Two } 5 \mathrm{~V} \text { External power } \\
\text { sources and connection was } \\
\text { via Breadboard }\end{array}$ & $\begin{array}{l}\text { Single External power source powering } \\
\text { the NodeMCU Baseboard with } 5 \mathrm{~V} \text { voltage } \\
\text { regulator }\end{array}$ \\
\hline 3. & Rack Arrangement & Vertical arrangement & $\begin{array}{l}\text { Horizontal arrangement to allow optimal } \\
\text { airflow and to avoid wetting the mushroom } \\
\text { block during rainfall }\end{array}$ \\
\hline 4. & $\begin{array}{l}\text { Water Nozzle } \\
\text { Placement }\end{array}$ & $\begin{array}{l}\text { Nozzle was not installed to } \\
\text { spray the roof }\end{array}$ & Installed nozzle to spray water on the roof \\
\hline
\end{tabular}

\section{System Implementation}

This section discusses how the enhanced IOT-based climate control system was implemented in the real-world setup as a proof of concept.

\section{The Mushroom House Setup}

The IoT-based climate control system was implemented in a real-world mushroom house located at NASOM Centre in Bandar Puteri, Klang, Malaysia. Thus, the result collected in this paper is based on real-world results. The mushroom house utilised the unused community space at the NASOM Centre to generate income for the autism centre. The mushroom house was built on a brick structure at the bottom and wired fencing reaching the roof to ensure better air circulation. These wired fences were covered with black netting to prevent direct sunlight that is not conducive for oyster mushroom growth. In addition, the water mist spraying system surrounded the floor and roof of the mushroom house to reduce the house's temperature. Figure 13 shows the implementation of the mushroom house with black netting and water mist spraying surrounding the structure. Figure 14 depicts the racks inside the mushroom house that are partially stocked with 500 growing mediums. In Figure 15, the IoT control box that automatically controls the climate inside 


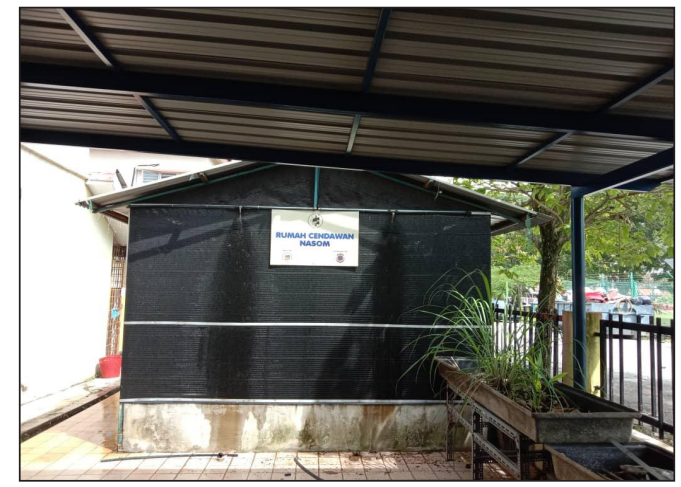

Figure 13. Smart Mushroom house situated on the unused community space

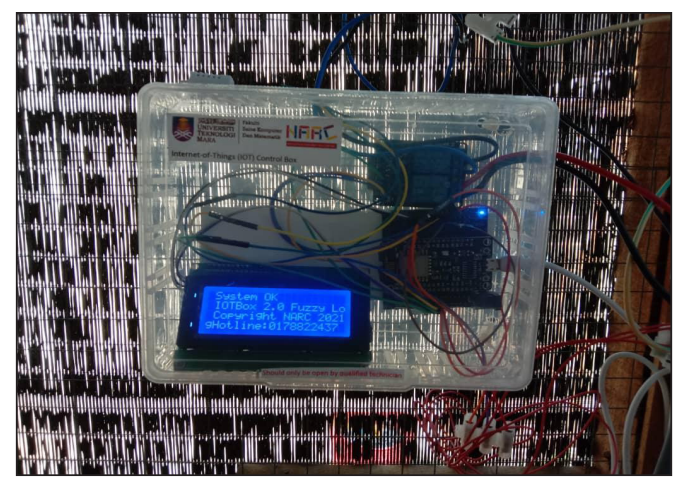

Figure 15. IoT control box for the system

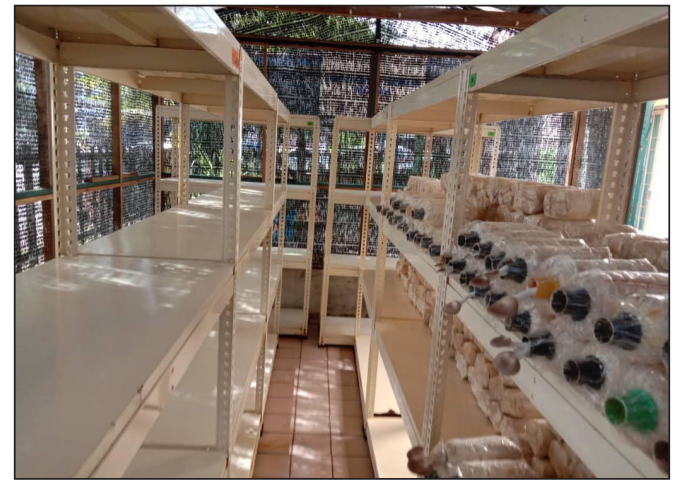

Figure 14. Setup of the racks inside the mushroom house

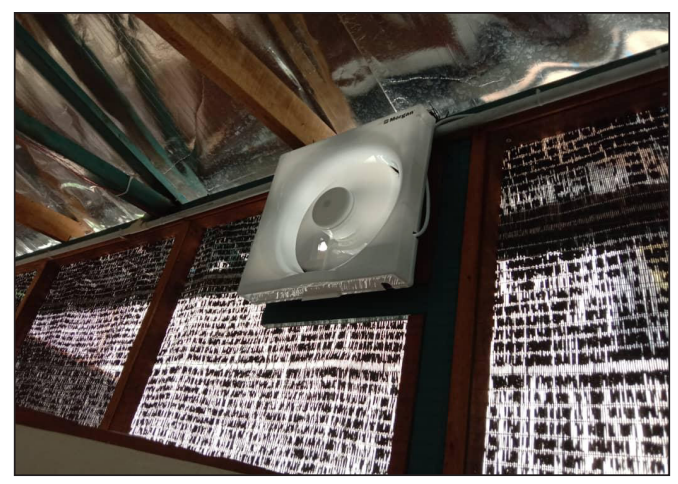

Figure 16. Ventilation fan to cool down the temperature and for air circulation

the mushroom house is displayed. Finally, Figure 16 shows the ventilation fan mounted on the wall to cool down the internal temperature and ensure good air circulation.

\section{Deployment of IoT-Based Climate Control System}

The IoT control box was deployed in the house and connected to a relay. Figure 17 shows the flow chart of the system. Upon booting up, the system waited for $5 \mathrm{~s}$ to ensure the DHT22 sensor could provide a reading for temperature and humidity. If the reading was not NULL, the system calculated the average value for temperature and humidity from the two sensors and displayed it on the LCD and the web interface. Next, the system converted the average temperature and crisp humidity values into fuzzy values and processed them into crisp output based on the fuzzy logic algorithm. The inference made by the fuzzy rules determined whether to turn the water pump and ventilation fan on or off. The result of the inference was displayed on the LCD and the web interface. The system also implemented a safety measure by using an increment to a program counter. If the counter reached above the value of 3 , the system paused for an hour to ensure that it did not repeat too many 
Muhammad Azizi Mohd Ariffin, Muhammad Izzad Ramli, Zarina Zainol, Mohd Nazrul Mohd Amin, Marina Ismail, Rosanita Adnan, Nor Diana Ahmad, Norhasiah Husain and Nursuriati Jamil

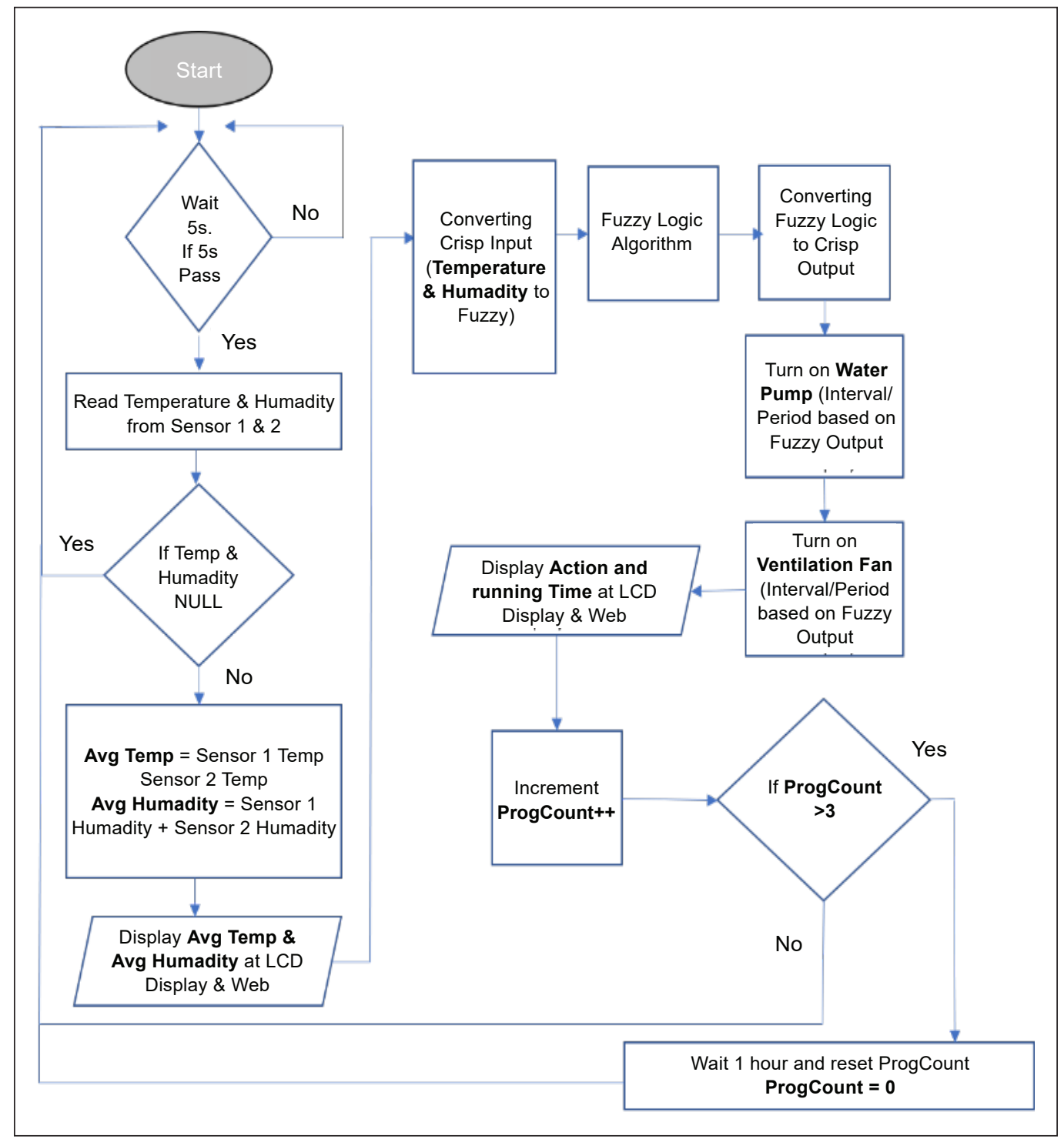

Figure 17. Flowchart of the climate control system

actions. Too many repeated actions may overheat the controller, and continuous running of the water pump will cause water wastage.

The fuzzy logic algorithm implemented 25 fuzzy rules derived from the simulation conducted in MATLAB to determine the duration of operating the water pump and ventilation fan. All the rules were coded using C language using Arduino IDE into the Arduino compatible microcontroller, NodeMCU. The snippet of the code is shown as Algorithm 1. The fuzzy logic was encapsulated in a function that can be invoked every time the microcontroller obtained the crisp temperature and humidity readings. 


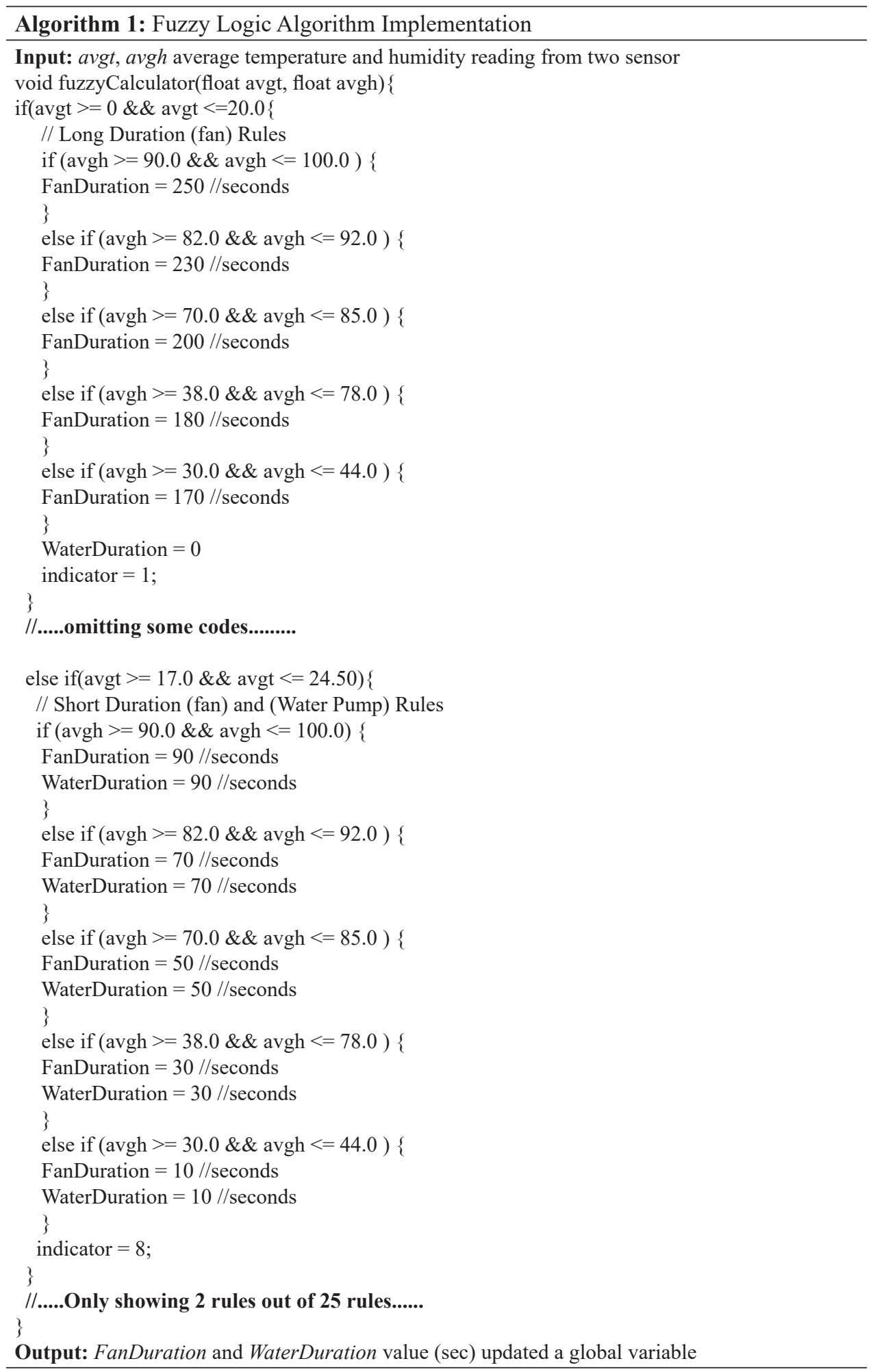




\section{RESULTS AND DISCUSSION}

The previous IoT-based climate control system using a fixed threshold started in late November 2020, and the enhanced climate control system using fuzzy logic began in January 2021 (Ariffin et al., 2020). This section presents the data captured before and after implementing the enhanced IoT-based climate control system using fuzzy logic. The findings are discussed according to the following criteria:
i. Water utilisation.
ii. Temperature.
iii. Humidity.
iv. Mushroom harvest per month.

\section{Water Utilisation}

The water utilisation for December 2020 and January 2021 were recorded based on the utility bill generated from the Air Selangor customer portal. The bill reflected the total water usage for both the mushroom house and the daycare centre. Since there was no student's activity since November 2020 due to the movement control order as stipulated by the government and the number of households remained the same in the daycare centre, it can be concluded that the decrease in water utilisation was due to the implementation of the enhanced climate control system in the mushroom house.

From November 2020 until December 2020, the system is still running the current IoT system with threshold-based logic. In January 2021, the system has replaced with the newly enhanced system with fuzzy logic. Figure 18 shows a significant decrease in water consumption from $20.0 \mathrm{~m}^{3}$ in December 2020 to $12.0 \mathrm{~m}^{3}$ in January 2021, indicating that the enhanced climate control system can reduce water consumption. In Table 5 , a substantial $40 \%$ saving of both water utilisation and total bills in January 2021 can be seen.

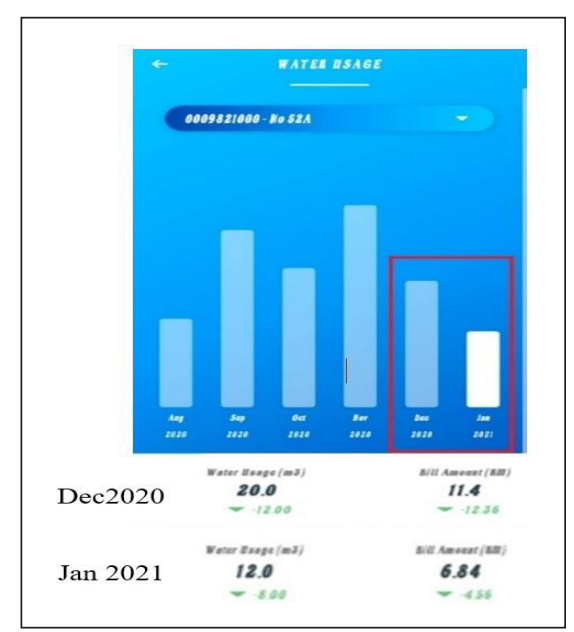

Figure 18. Water usage and bill amount for December 2020 and January 2021

Table 5

Percentage of savings after the implementation of the Fuzzy Logic approach

\begin{tabular}{lcccc}
\hline & \multicolumn{2}{c}{ Month } & \multirow{2}{*}{ Differences } & Savings (\%) \\
\cline { 2 - 3 } & December 2020 & January 2021 & & 8.0 \\
\hline Water Usage $\left(\mathrm{m}^{3}\right)$ & 20.0 & 12.0 & & 40 \\
Bill Amount $(\mathrm{RM})$ & 11.4 & 6.84 & 4.56 & 40 \\
\hline
\end{tabular}




\section{Temperature and Humidity Control}

In addition to water utilisation, temperature and humidity were also recorded. Thus, we performed a comparative analysis before and after the fuzzy logic algorithm was embedded in the enhanced climate control system. The 'before' readings were extracted from (Ariffin et al., 2020). Figures 19 and 20 show the results of average temperature and humidity monitored for six days, respectively. The temperature and humidity readings were taken three times a day, specifically at $10.00 \mathrm{am}, 12.00$ noon, and $2.00 \mathrm{pm}$. Then the average was calculated.

The graph in Figure 19 shows that the average temperature was lower most of the days after implementing the fuzzy logic algorithm in the enhanced system. It indicated that the ideal temperature for mushroom cultivation was achieved with the enhanced climate control system. The temperature on day 2 was slightly higher than the day before. However, the average reading for all six days proved that the fuzzy logic embedded in the enhanced

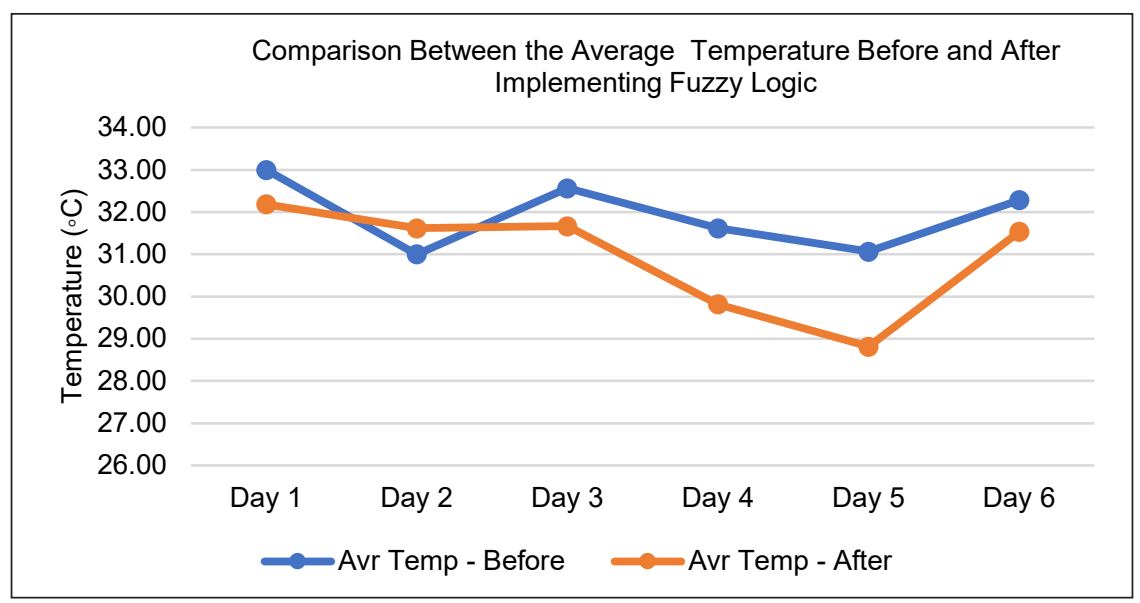

Figure 19. Average temperature before and after implementing Fuzzy Logic

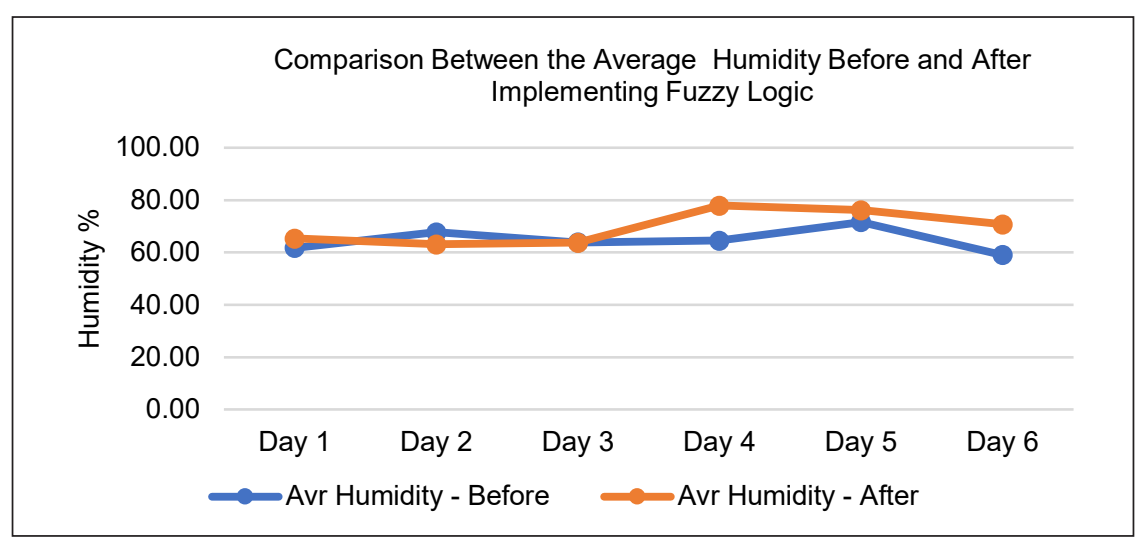

Figure 20. Average humidity before and after implementing Fuzzy Logic 
climate control system assisted the temperature management in the mushroom house. The same result appeared in the average humidity graph in Figure 20. Except for day 2, the average humidity was equal to or higher after implementing the fuzzy logic algorithm. These results proved that embedding fuzzy logic in the enhanced climate control system facilitated maintaining and controlling the ideal humidity for mushroom cultivation.

\section{Mushroom Harvest or Yield}

A full month mushroom yield was recorded for December 2020 and February 2021. However, due to replacing the previous climate control system with the enhanced system, we omitted the yield for January 2021. As a result, the production of mushrooms increased dramatically from $4.260 \mathrm{~kg}$ in December to $10.470 \mathrm{~kg}$ in February 2021, as shown in Table 6 . The $226 \%$ increase of mushroom yield proved that the success of environmental management after implementing the fuzzy logic algorithm had promoted mushroom growth to the optimum.

Table 6

Total mushroom harvested before and after the implementation of the Fuzzy Logic approach

\begin{tabular}{|c|c|c|c|c|}
\hline & \multicolumn{2}{|c|}{ Month } & \multirow{2}{*}{ Differences } & \multirow{2}{*}{ Increase of harvest $(\%)$} \\
\hline & December 2020 & February 2021 & & \\
\hline Total Harvest (kg) & 4.620 & 10.470 & 6.210 & 226 \\
\hline
\end{tabular}

\section{CONCLUSION}

The cultivation of oyster mushrooms was successfully implemented at NASOM's Autism Care Centre in Bandar Puteri Klang, Malaysia. It has helped the centre generate sustainable income via urban farming. Using a fuzzy logic algorithm and improving both the climate control system and physical internal design of the mushroom house has shown promising results based on the mushroom yield and water saving. The enhanced IoT-based climate control system has been running successfully for more than six months and has produced cumulatively $43.460 \mathrm{~kg}$. On the other hand, there is still room for improvement. Since the IoT-based climate control system was deployed in the real environment, many unexpected, unforeseen circumstances have occured. For example, the mushroom house is located near a busy road, emissions from vehicles may cause an increase in air pollutants. Our next step is to investigate further the level of carbon dioxide, carbon monoxide or other chemical matters and recommend different technologies to be implemented.

\section{ACKNOWLEDGEMENT}

The authors would like to extend appreciation to National Autism Resource Center (NARC) and the Faculty of Computer and Mathematical Sciences, UiTM Shah Alam, for supporting this project by providing a research grant (600-TNCPI/PBT 5/3 (017/2020)). 


\section{REFERENCES}

Adenugba, F., Misra, S., Maskeliūnas, R., Damaševičius, R., \& Kazanavičius, E. (2019). Smart irrigation system for environmental sustainability in Africa: An internet of everything (IoE) approach. Mathematical Biosciences and Engineering, 16(5), 5490-5503. https://doi.org/10.3934/mbe.2019273

Adhitya, R. Y., Ramadhan, M. A., Kautsar, S., Rinanto, N., Sarena, S. T., Munadhif, I., Syai'In, M., Soelistijono, R. T., \& Soeprijanto, A. (2017). Comparison methods of fuzzy logic control and feed forward neural network in automatic operating temperature and humidity control system (Oyster mushroom farm house) using microcontroller. In 2016 International Symposium on Electronics and Smart Devices (ISESD) (pp. 168-173). IEEE Publishing. https://doi.org/10.1109/ISESD.2016.7886713

Algarín, C. R., Cabarcas, J. C., \& Llanos, A. P. (2017). Low-cost fuzzy logic control for greenhouse environments with web monitoring. Electronics, 6(4), Article 71. https://doi.org/10.3390/electronics6040071

Alpay, Ö., \& Erdem, E. (2018). The control of greenhouses based on fuzzy logic using wireless sensor networks. International Journal of Computational Intelligence Systems, 12(1), 190-203. https://doi.org/10.2991/ ijcis.2018.125905641

Al-Saidi, M., \& Elagib, N. A. (2017). Towards understanding the integrative approach of the water, energy and food nexus. In Science of the Total Environment (Vol. 574, pp. 1131-1139). Elsevier. https://doi. org/10.1016/j.scitotenv.2016.09.046

Ariffin, M. A. M., Ramli, M. I., Amin, M. N. M., Ismail, M., Zainol, Z., Ahmad, N. D., \& Jamil, N. (2020). Automatic climate control for mushroom cultivation using IoT approach. In 2020 IEEE 10th International Conference on System Engineering and Technology (ICSET) (pp. 123-128). IEEE Publishing. https://doi. org/10.1109/ICSET51301.2020.9265383

Boonchieng, E., Chieochan, O., \& Saokaew, A. (2018). Smart farm: Applying the use of NodeMCU, IOT, NETPIE and LINE API for a Lingzhi mushroom farm in Thailand. IEICE Transactions on Communications, E101B(1), 16-23. https://doi.org/10.1587/transcom.2017ITI0002

Chieochan, O., Saokaew, A., \& Boonchieng, E. (2017). IOT for smart farm: A case study of the Lingzhi mushroom farm at Maejo University. In 2017 14th International Joint Conference on Computer Science and Software Engineering (JCSSE) (pp. 1-6). IEEE Publishing. https://doi.org/10.1109/JCSSE.2017.8025904

CircuitSchools Staff. (2020). DHT22 temperature and humidity sensor. Retrieved June 29, 2021, from https:// www.circuitschools.com/dht22-temperature-and-humidity-sensor/

Climate-Data.org. (2021). Kuala Lumpur climate: Average temperature, weather by month, Kuala Lumpur weather averages. Retrieved February 28, 2021, from https://en.climate-data.org/asia/malaysia/kualalumpur/kuala-lumpur-715107/\#climate-graph

Cruz-Del Amen, J. D., \& Villaverde, J. F. (2019). Fuzzy logic-based controlled environment for the production of oyster mushroom. In 2019 IEEE 11th International Conference on Humanoid, Nanotechnology, Information Technology, Communication and Control, Environment, and Management (HNICEM) (pp. 1-5). IEEE Publishing. https://doi.org/10.1109/HNICEM48295.2019.9072902

Hamidizade, M., Taghavi, S. M., Martins, S. J., Herschlag, R. A., Hockett, K. L., Bull, C. T., \& Osdaghi, E. (2020). Bacterial brown pit, a new disease of edible mushrooms caused by mycetocola sp. Plant Disease, 104(5), 1445-1454. https://doi.org/10.1094/PDIS-10-19-2176-RE 
Muhammad Azizi Mohd Ariffin, Muhammad Izzad Ramli, Zarina Zainol, Mohd Nazrul Mohd Amin, Marina Ismail, Rosanita Adnan, Nor Diana Ahmad, Norhasiah Husain and Nursuriati Jamil

Hendrawan, Y., Anta, D. K., Ahmad, A. M., \& Sutan, S. M. (2019). Development of fuzzy control systems in portable cultivation chambers to improve the quality of oyster mushrooms. IOP Conference Series: Materials Science and Engineering, 546(3), Article 032013. https://doi.org/10.1088/1757899X/546/3/032013

Ibrahim, N. H. N., Brahim, A. R., Mat, I., Harun, A. N., \& Witjaksono, G. (2018). IR 4.0 using IoT and LORAWAN to accelerate Lentinula Edodes growth. In 2018 2nd International Conference on Smart Sensors and Application (ICSSA) (pp. 28-32). IEEE Publishing. https://doi.org/10.1109/ICSSA.2018.8535954

Kashyap, M., Sharma, V., \& Gupta, N. (2018). Taking MQTT and NodeMcu to IOT: Communication in internet of things. Procedia Computer Science, 132, 1611-1618. https://doi.org/10.1016/j.procs.2018.05.126

Kassim, M. R. M., Mat, I., \& Yusoff, I. M. (2019). Applications of internet of things in mushroom farm management. In 2019 13th International Conference on Sensing Technology (ICST) (pp. 1-6). IEEE Publishing. https://doi.org/10.1109/ICST46873.2019.9047702

Krishnan, R. S., Julie, E. G., Robinson, Y. H., Raja, S., Kumar, R., Thong, P. H., \& Son, L. H. (2020). Fuzzy logic based Smart Irrigation System using Internet of Things. Journal of Cleaner Production, 252, Article 119902. https://doi.org/10.1016/j.jclepro.2019.119902

Li, S., Ding, X., Kuang, Q., Ata-UI-Karim, S. T., Cheng, T., Liu, X., Tian, Y., Zhu, Y., Cao, W., \& Cao, Q. (2018). Potential of UAV-based active sensing for monitoring rice leaf nitrogen status. Frontiers in Plant Science, 9, Article 1834. https://doi.org/10.3389/fpls.2018.01834

Mat, I., Kassim, M. R. K., Harun, A. N., \& Yusoff, I. M. (2019). Smart agriculture using internet of things. In 2018 IEEE conference on open systems (ICOS) (pp. 54-59). IEEE Publishing. https://doi.org/10.1109/ ICOS.2018.8632817

Najmurrokhman, A., Kusnandar, Daelami, A., Nurlina, E., Komarudin, U., \& Ridhatama, H. (2020). Development of temperature and humidity control system in Internet-of-Things based oyster mushroom cultivation. In 2020 3rd International Seminar on Research of Information Technology and Intelligent Systems (ISRITI) (pp. 551-555). IEEE Publishing. https://doi.org/10.1109/ISRITI51436.2020.9315426

Navarro, E., Costa, N., \& Pereira, A. (2020). A systematic review of IoT solutions for smart farming. Sensors, 20(15), Article 4231. https://doi.org/10.3390/s20154231

Nongthombam, J., Kumar, A., Ladli, B., Madhushekhar, M., \& Patidar, S. (2021). A review on study of growth and cultivation of oyster mushroom. Plant Cell Biotechnology and Molecular Biology, 22(5\&6), 55-65.

Poulsen, M. N., Neff, R. A., \& Winch, P. J. (2017). The multifunctionality of urban farming: Perceived benefits for neighbourhood improvement. Local Environment, 22(11), 1411-1427. https://doi.org/10.1080/1354 9839.2017.1357686

Revathi, S., \& Sivakumaran, N. (2016). Fuzzy based temperature control of greenhouse. IFAC-PapersOnLine, 49(1), 549-554. https://doi.org/10.1016/j.ifacol.2016.03.112

Saw S. H. (2007). The population of Peninsular Malaysia. Institute of Southeast Asian Studies.

Shakir, A. A., Hakim, F., Rasheduzzaman, M., Chakraborty, S., Ahmed, T. U., \& Hossain, S. (2019). Design and implementation of SENSEP ACK: An IoT based mushroom cultivation monitoring system. In 2019 
International Conference on Electrical, Computer and Communication Engineering (ECCE) (pp. 1-6). IEEE Publishing. https://doi.org/10.1109/ECACE.2019.8679183

Tang, K. H. D. (2019). Climate change in Malaysia: Trends, contributors, impacts, mitigation and adaptations. In Science of the Total Environment (Vol. 650, pp. 1858-1871). Elsevier. https://doi.org/10.1016/j. scitotenv.2018.09.316

Wahab, H. A., Manap. M. Z. I. A., Ismail, A. E., Ong, P., Ismon, M., Zainulabidin, M. H., Noor, F. M., \& Mohamad, Z. (2019). Investigation of temperature and humidity control system for mushroom house. International Journal of Integrated Engineering, 11(6), 27-37. https://doi.org/10.30880/ijie.2019.11.06.004

Wong, C. L., Liew, J., Yusop, Z., Ismail, T., Venneker, R., \& Uhlenbrook, S. (2016). Rainfall characteristics and regionalization in Peninsular Malaysia based on a high resolution gridded data set. Water, 8(11), Article 500. https://doi.org/10.3390/w8110500

Xia, J., Yang, Y., Cao, H., Zhang, W., Xu, L., Wang, Q., Ke, Y., Zhang, W., Ge, D., \& Huang, B. (2018). Hyperspectral identification and classification of oilseed rape waterlogging stress levels using parallel computing. IEEE Access, 6, 57663-57675. https://doi.org/10.1109/ACCESS.2018.2873689 
